JD

75,1

164

Received 24 June 2018

Revised 30 August 2018

Accepted 1 September 2018

\section{The foundation of information science: one world or three? A discussion of Gnoli (2018)}

\author{
Birger Hjørland \\ Department of Information Studies, University of Copenhagen, Copenhagen, Denmark
}

\begin{abstract}
Purpose - The purpose of this paper is to make a critical analysis of the views put forward by Claudio Gnoli (2018) in this paper concerning philosophical problems in library and information science (LIS).

Design/methodology/approach - The paper presents the basic ideas in Gnoli (2018) and discusses the set of basic assumptions, concepts and conclusions put forward.

Findings - It is argued that the idea of the theory of levels is basically sound, but we do not need to consider the material world, the mental world (minds) and the world of mentefacts as three different worlds. They represent different levels with different kinds of emergent properties in the world. Further, although the concepts of artifacts and mentefacts are useful, there are other terms within LIS, such as document, work and object that have been influential and should be discussed in this context. It is also argued that subjective vs objective knowledge is often confused with private vs public knowledge, which is problematic. Finally, it is claimed that the cognitive view and the "sociological view" are not about two different levels of reality but are competing views about the same reality. Originality/value - The paper clarifies some aspects of the analytical framework of domain analysis and adds to the developments of the philosophical dimensions of information within LIS.
\end{abstract}

Keywords Cognition, Information science, Theory, Documents, Epistemology, Information research Paper type Conceptual paper

\section{Introduction}

Gnoli (2018) suggested a synthesis of the cognitive and the sociological view in library and information science (LIS) and knowledge organization (KO) based on, among other, Karl R. Popper's "three worlds" metaphysics and on the concept of mentefact. The paper represents a fine piece of scholarship on an important and difficult subject and the careful study of the theory of mentefact provide useful information about a neglected concept.

The present paper demonstrates that another philosophical perspective of the mind, monism, may solve the same problems in a more satisfactory way. In addition, it is claimed that the concepts document and work, within a monistic framework, are able to contribute to solve the issues, which Gnoli uses in his argument for Popper's "world three.”

\section{Gnoli's main arguments}

Gnoli (2018, pp. 1227-1228) argued from the perspective of levels of reality:

The theory of levels of reality (Poli, 2001) provides an important intellectual tool to better analyze the relationships holding between different principles of explanation. This theory identifies a series of different levels in reality, each resting on lower levels but also showing novel emergent properties that are not owned by the lower levels. Among the main levels that are commonly acknowledged by most authors are matter, life, mind, and society.

Gnoli further argues that the cognitive approach in LIS emphasizes the role of mind in the production, organization and retrieval of information while the sociological[1] one - which is

(C) Birger Hjørland. Published by Emerald Publishing Limited. This article is published under the Creative Commons Attribution (CC BY 4.0) licence. Anyone may reproduce, distribute, translate and create derivative works of this article (for both commercial and non-commercial purposes), subject to full attribution to the original publication and authors. The full terms of this licence may be seen at http://creativecommons.org/licences/by/4.0/legalcode 
identified with Hjørland (2002b) - emphasizes the role of society. The overall claim by Gnoli (2018) is that each of these views only represents a partial picture, and they need to be united by a more general theoretical frame of reference, which he then outlines. He wrote: "Clearly, however, both mind and society are involved in these processes and interact through inter-level relationships."

The theoretical frame that Gnoli introduces for this purpose focuses on the philosophy of Nicolai Hartmann and Karl Popper and these two philosophers are considered similar in relation to his main argument. About Hartmann is written:

Hartmann identifies four major levels ("strata") in reality: the material, the organic, the psychic and the spiritual. Information, knowledge and their organization belong to the spiritual level. Hartmann's term spirit (Geist) comes from the German philosophical tradition and should be understood in a broad sense, involving not just spirituality or religious phenomena but anything related to human culture.

The stratum of spirit is further analyzed by Hartmann into three layers: " $t$ the category of the spirit is divided into personal, objective and objectivated spirit. Personal spirit is the spirit of the individual; objective spirit is the living spirit of communities; and objectivated spirit characterizes the products of spirit" (Poli, 2016). These three layers of spirit offer a suitable model for analyzing the phenomenon of knowledge. Indeed, personal spirit, [...], has to do with the knowledge of individual information users that is focused in the cognitive approach; objective spirit has to do with the social sharing of knowledge as focused in the sociological approach; and objectivated spirit has to do with the structure of knowledge in itself, as a product of humans subsisting after separation from its original producers. (Gnoli, 2018, p. 1228)

Here follows Gnoli's main conclusion:

Unlike those of personal spirit and objective spirit, the layer of objectivated spirit has not been considered by mainstream approaches in information science widely enough. This may be due to implicit reference to ontologies not acknowledging any more layer over the social one, as it will be seen in section 5 . However, the framework of levels theory suggests that the layer of objectivated spirit should also be considered, in order to build a more complete theory of LIS and KO.

Popper's philosophy is by Gnoli (2018, p. 1229) considered to support the same main conclusions:

Karl Popper's notions of "objective knowledge" and of "World 3" (Popper, 1972, 1978, 1992), which also refers to the products of thought as entities autonomous from the material and mental levels that have produced them. The three "worlds" postulated in this model are broadly listed by Popper as those of matter, of consciousness and of culture (Popper and Eccles, 1977, part 1). Popper's epistemology is especially concerned with the nature of knowledge and its development through theories. To him, theories belong to World 3 and as such have an autonomous status, similar to objectivated spirit, so that once a theory has been formulated, its full properties can be discovered and considered even independently from the particular conception of its original creator. For example, a theoretical physicist may postulate the existence of certain particles that behave according to some mathematical laws; then, on the basis of these laws, another physicist can predict that the particles will behave in a given way, and yet another team of scientists can perform an experiment trying to detect such predicted behaviour, in order to corroborate or falsify the theory: the experiment was not imagined by the original proposer, but has emerged later as a consequence of the theory itself.

In summary, Gnoli claims that the cognitive and "the sociological" approach to information science is each about a certain level of reality and that the lack of a higher level that the social has brought about a neglect of probably the most important object for information science: the structure of knowledge in itself.

\section{Discussion of Gnoli's metaphysical standpoint}

I have no argument toward the theory of levels of reality, although it should be recognized that there is no consensus on which layers exist, and how then can be identified and thus how disagreements may be solved (see Kleineberg, 2017 for a fine review). In fact, Hjørland 
(2002c) was a defense of a specific theory of psychological levels suggested by Leontyev (1981), which is based on monism (materialism) and thereby seems to solve some of the theoretical problems inherent in, for example, Popper's metaphysics.

Monism is the theory that there is only one fundamental kind, category of thing or principle. It contrasts with dualism, the theory that there are two fundamental kinds of things or principles and, less commonly, with pluralism, which is the view that there are many kinds or categories (cf. Robinson, 2017). There are many kinds of monism, dualism and pluralism[2], for this paper the discussion is limited to the philosophy of mind, the theoretical issue whether the mental and the physical, or mind and body or mind and brain should be understood as involving one, two or more fundamental worlds.

On this point Gnoli supports Popper's pluralism (and thereby also his dualism). From the point of view of evolutionary theory, pluralism seems, however, problematic, even supernatural and superstitious (cf. Bunge 1979, p. 56). Charles Darwin maintained that biological evolution is not just about the development of anatomy and physiology, but also about the development of mind and behavior. In that framework both animals and humans have minds (although at different developmental stages)[3], and "mind" should not be understood as something different from "matter," but as a certain evolutionary product of matter (and thus there is no dualism). Popper developed his dualism together with Sir John Eccles, about which Bunge (1979, p. 56) wrote:

There is no justification for a philosopher to continue to talk of mind as a human prerogative as well as immaterial and unchanging, let alone as supernatural. There is even less justification for a neuroscientist to continue to hold such prescientific views on mind. However this is exactly what the eminent neurophysiologist Sir John Eccles has been saying for the past three decades: that mind is immaterial yet can act on neurons (Eccles, 1951, 1980); and that the existence of consciousness and that of the cosmos "require a supernatural explanation to be admitted by we scientists in all humility".[13] Not surprisingly, Eccles claims that Homo sapiens has not been subject to evolution [...].

I agree with Poli (2001) that minds and societies coevolve, hence are reciprocally dependent. Gnoli seems to disagree, writing "if 'minds' are allowed to include awareness in animals, they clearly precede the development of civil 'societies' based on human languages." But animals have also developed mechanisms to coordinate social behavior, and one may here see a first sign of Gnoli's argumentation that the cognitive view is one level in LIS associated with human minds, whereas the sociological theory in LIS is about another, independently perceived level associated with societies.

Thus, minds in general, including the human mind, must be understood as something that has evolved because animals with different levels of psychological development have had a better chance to accommodate to the environment (both to the physical, the biological and the social environment). Also "world three" (or "the objectivated spirit" or "artefacts and mentefacts") must be understood as part of the higher forms of evolution, i.e. as a part of the material world, monistically). Artifacts cover all physical objects made by man, including man-made modifications of any materials of nature. Mentefacts, on the other hand, are the non-material creations like theories or a fuge of Bach. Mentefacts have specific manifestations in artifacts or in learned behaviors and memory. I shall relate these two concepts to related concepts developed within LIS.

One of these concepts is document (corresponding to artifact), which has received great attention in LIS and which many authors, including Buckland (1991, 2017), Frohmann (2004), Furner (2004), Hjørland (2000), Lund (2009) and Ørom (2007), have argued should be considered the core concept of LIS. Document has been defined as "any concrete or symbolic indication, preserved or recorded, for reconstructing or for proving a phenomenon, whether physical or mental" (Briet, 1951, p. 7; here quoted from Buckland, 1991, p. 47). Another concept is work, which has received much attention in relation to cataloging theory (Žumer, 2018; Smiraglia 2001, 2002), and in this connection the IFLA Library Reference 
Model (LRM), which represents a high-level conceptual model based on the principle of entity-relationship modeling. It seems to provide deeper knowledge about the relations between mentefacts and artifacts in relation to LIS. Objects (informative objects, information objects) should also be mentioned. Not just artifacts, but any kinds of objects should be considered in the context of LIS, as Buckland (1991, p. 50; italics in original) stated: "We conclude that we are unable to say confidently of anything that it could not be information." In relation to objects in general it should be considered that libraries, archives and museums are increasingly studied together, thus including all kinds of museum objects as kinds of documents.

About world three Gnoli wrote:

Popper's epistemology is especially concerned with the nature of knowledge and its development through theories. To him, theories belong to World 3 and as such have an autonomous status, similar to objectivated spirit, so that once a theory has been formulated, its full properties can be discovered and considered even independently from the particular conception of its original creator. For example, a theoretical physicist may postulate the existence of certain particles that behave according to some mathematical laws; then, on the basis of these laws, another physicist can predict that the particles will behave in a given way, and yet another team of scientists can perform an experiment trying to detect such predicted behaviour, in order to corroborate or falsify the theory: the experiment was not imagined by the original proposer, but has emerged later as a consequence of the theory itself.

To analyze this quote, we will make some further theoretical distinctions. A theory in the mind of a scientist is part of that scientist's mind, that is, it belongs to Poppers "world 2." The theory may be recorded or non-recorded. The recorded version may be in non-published documents or publications. If it is not communicated to anybody, it is a private theory, if it is communicated to others, it is a public theory (which comes in degrees, if it is published in a leading journal, it becomes much more public than if just communicated to a few persons). The intervention of printing meant that scientists could rely on having access to identical recorded of public sources, which meant much for the development of trustworthy scholarly communication and source-criticism. The basic function of science and scholarship is intimately related to the public nature of supporting and communicating claims and thereby make the subject to criticism by other scholars. In the case of important scientists and scholars, much work is usually done by scholars, libraries and archives to trace and record both their non-published documents and their publications, and, for example, make them available in text-critical editions. Often such work is done long time after the death of the author, and the discovery of new, formerly unpublished works, may change the interpretation of the work of the author at a much later point in time. Compared to Popper's theory as described in the quote above, this means that it is the public nature of scientific theories that allows for their further developments by other scientists. This conceptual framework with private and public knowledge, documents and publications provides a more naturalistic description of the development of knowledge and theories. This description does not understand the researchers' subjective world and the world of recorded knowledge as two different worlds, but as kinds of processes, things, symbolic systems and meanings historically developed in the world. These elements of the scholarly system have from the start been parts of the sociological/domain-analytic framework for LIS.

The concepts "subjective knowledge" and "objective knowledge" (as used by Popper and Gnoli) are problematic in this context, because also published knowledge is always subjective in the sense that it reflects the subjectivity of its originator. In the ground swell of Kuhn (1962) it is broadly accepted that scientific knowledge represents the theoretical view, tradition and paradigm of its originator. Kuhn contributed to a historical and social dimension in epistemology that is absent in positivism as well as in Popper's critical rationalism. Even if there is consensus in a community of researchers, this does not guarantee the objectivity of the knowledge claims because the whole community may be dominated by a view, that later may
A discussion of Gnoli (2018) 
JD

75,1

168

be modified and therefore the first view is now considered subjective, i.e. as representing the views of its authors, their tradition and zeitgeist.

We have thus development of layers, the physical world, the biological world (with minds from a certain stage of development) and the social and cultural world (also with minds). The biological world, the world of minds and the sociocultural world can be understood from a monistic perspective as the development of new levels with new emergent properties.

\section{The cognitive, the domain-analytic and other views}

Which are the major "views," metatheories, traditions or paradigms in LIS? Hjørland (2018c, Section 3) presented the following positions:

(1) An atheoretical paradigm.

(2) Information theory.

(3) The Cranfield tradition (3.1 The bibliographic paradigm).

(4) The cognitive view.

(5) Floridi's philosophy of information.

(6) Social, culturally and content-informed views (with domain analysis).

These positions are not satisfactory described today, there are often conflicting views of their basis as well as for their implications for LIS. There is a need for better clarification, but researchers may not always want to make clear analysis but may want to protect a given position from criticism.

We saw above that Gnoli (2018) considered the cognitive view as being about a specific level (minds), whereas the domain-analytic level was understood as being about the social level (he did not consider whether information theory and/or the Cranfield tradition is about the level of matter). One of the things needed to illuminate such claim is the presentation of a specific investigation from each position and an analysis of its implication for concrete applications. Ellis (1992, p. 53) tried that when comparing the Cranfield tradition with the cognitive view, but he found that it is:

$[\ldots]$ difficult to identify [...] that there is any concrete scientific achievement which can be said to serve as the exemplar for the cognitive approach, and which would qualify as a paradigm for that approach [...] unlike the physical paradigm there may be no equivalent of the Cranfield tests to serve as a paradigm for those adopting the cognitive approach in this field.

One of the basic criticisms raised against the cognitive paradigm by Hjørland (2018b, Section 3.2.1) was:

Based on this insight, the cognitive view seems paradoxical. Schools of LIS have for a long time before the cognitive view was developed studied and taught indexing. If it is assumed that indexers are influenced by what they have learned about indexing, how then, can LIS learn what should be taught by studying mental processes of people (whether or not they have received training in indexing)? The mental processes are not universal principles hard-wired in the human brain but are learned and thus socially formed principles influenced by prevailing theories and technologies.

However, Gnoli's article does not relate to such specific issues concerning the two approaches he characterizes and try to unite. The difference seems not so much to be about two different levels (the mental and the social) as between two different ways of understanding the mental: in the cognitive view as universal rules in the mind to uncover, in the domain-analytic view as formed by people's socialization in different cultures, domains and paradigms. How would Gnoli unite the cognitive view of indexing and the domain-analytic view of indexing to a higher level? In my view this is not possible. 


\section{Conclusion}

LIS is very much about human interaction with the universe of recorded knowledge, which should not be confused with human interacting with computers, even if the computer today (and in the future) is the totally dominant medium for this interaction. LIS approaches its problem from the study of the universe of recorded knowledge, its kinds, genres, paradigms, potentials, conflicts, etc., the systems of producers, mediators, institutions and users. From this position we are interested in how this knowledge is represented and organized and to contribute to its optimal use. All specific technologies are (or should be) considered in this perspective. This is an inherent social and cultural perspective. However, the issue that may rightly worry Gnoli is a tendency in the field to replace psychologism with sociologism[4]. This is a relevant caution that Gnoli (2018) supports.

\section{Notes}

1. Gnoli speaks of the sociological approach with reference to Hjørland (2002b), which, however, used the term "the socio-cognitive perspective". This term indicates that it is not just about the sociological level, but also about the cognitive. To underline that the focus is knowledge-domains, the term "the domain-analytic approach" is also used (e.g. Hjørland and Albrechtsen, 1995; Hjørland, 2002a, 2017). The term epistemology is mostly included in the description of this approach.

2. Of special relevance for information science is another kind of pluralism: The view that there are more ways to classify objects in the world. A leading representative of this view is John Dupré (e.g. 1990, 1993). Dupré advanced pluralist positions in both epistemology and metaphysics. He argues that the kinds named by conflicting systems of classification may all be real because they serve the various purposes of the humans classifying things. He calls his metaphysics "promiscuous realism" (Dupré, 1993). In information science, Jens-Erik Mai (e.g. 2011, 2013) has forcefully promoted this view.

3. Leontyev (1981) distinguishes five stages or levels of the development of psychological functions from primitive organisms to Homo sapiens (here quoted from Hjørland, 2002c): First, the stage of irritability is characteristic of the absorption of food particles through the surface of the body of one-celled animals. Leontyev does not see such behavior as evidence of something psychical (it is a pre-form of psychological behavior). Second, the stage of sensory psyche can be exemplified by insects, birds and fish. It is characterized by the ability of the organism to sense influences, but the animal cannot integrate different influences into a whole. Animals at this stage of development show stiff or rigid patterns of reactions, i.e., instinctive forms of behavior. Leontyev sees this stage as psychical in its most primitive form. Third, the stage of perceptual psyche is primarily characterized by the perception of objects. The organism is now not just limited to sensing and responding to sound, light, simple forms, etc., but perceives specific objects (e.g. flies). This allows much more flexible forms of behavior directed towards that object. Fourth, the stage of intellect is associated with actions, which presuppose the use of tools. The organism is no longer solely dependent on its own body. This stage is found in man and chimpanzees. Fifth, the stage of consciousness is specifically human. According to the theory of Leontyev, it is associated with language and societal production. What is described here can be interpreted as a theory of the development of biological stages of information utilization behavior from more primitive, specific and passive forms of sensing information towards more advanced, complex, flexible and active forms of information utilization.

4. Hjørland (2018a, p. 7) suggested the following positions (defending pragmatic realism): Positivism and näive realism: the world is as we immediately see it. We classify the world as it is (subjectivity can be and should be eliminated). Cognitivism and psychologism: the way we classify the world is determined by our given universal biological characteristics. Sociologism: the classification of things reproduces a pattern of social arrangements of the classifiers rather than a pattern of the things themselves. Pragmatic realism: the thing themselves cannot be distinguished from human practices. We classify things according to human needs, but still according to how the world is.
A discussion of Gnoli (2018) 
JD

75,1

\section{References}

Briet, S. (1951), Qúest-ce que la documentation?, Édition Documentaires Industrielles et Techniques, Paris.

Buckland, M.K. (1991), Information and Information Systems, Greenwood Press, New York, NY.

Buckland, M.K. (2017), "Document theory", in Hjørland, B. (Ed.), Knowledge Organization, ISKO Encyclopedia of Knowledge Organization, ISKO, Rome, in press, available at: www.isko.org/cyclo/ document

Bunge, M. (1979), "The mind-body problem in an evolutionary perspective”, in Wolstenholme, G. and O'Connor, M. (Eds), Brain and Mind: Ciba Foundation Symposium 69, Excerpta Medica, Amsterdam, pp. 53-78.

Dupré, J. (1990), "Scientific pluralism and the plurality of the sciences: comments on David Hull's science as a process", Philosophical Studies, Vol. 60 Nos 1-2, pp. 61-76.

Dupré, J. (1993), The Disorder of Things: Metaphysical Foundations of the Disunity of Science, Harvard University Press, Cambridge, MA.

Eccles, J.C. (1951), "Hypotheses relating to the mind-body problem", Nature, Vol. 168 No. 4263, pp. 53-64.

Eccles, J.C. (1980), The Human Psyche: The Gifford Lectures, University of Edinburgh 1978-1979, Springer, Berlin.

Ellis, D. (1992), "The physical and cognitive paradigms in information retrieval research", Journal of Documentation, Vol. 48 No. 1, pp. 45-64.

Frohmann, B. (2004), Deflating Information: From Science Studies to Documentation, University of Toronto Press, Toronto.

Furner, J. (2004), "Information studies without information”, Library Trends, Vol. 52 No. 3, pp. 427-446.

Gnoli, C. (2018), "Mentefacts as a missing level in theory of information science", Journal of Documentation, Vol. 74 No. 6, pp. 1226-1242, available at: https://doi.org/10.110 8/JD-04-2018-0054

Hjørland, B. (2000), "Documents, memory institutions, and information science", Journal of Documentation, Vol. 56 No. 1, pp. 27-41.

Hjørland, B. (2002a), "Domain analysis in information science: eleven approaches - traditional as well as innovative", Journal of Documentation, Vol. 58 No. 4, pp. 422-462.

Hjørland, B. (2002b), "Epistemology and the socio-cognitive perspective in information science", Journal of the Association for Information Science and Technology, Vol. 53 No. 4, pp. 257-270.

Hjørland, B. (2002c), "Principia informatica", in Bruce, H., Fidel, R., Ingwersen, P. and Vakkaril, P. (Eds), Emerging Frameworks and Methods: CoLIS 4: Proceedings of the Fourth International Conference on Conceptions of Library and Information Science, Libraries Unlimited, Seattle, WA and Greenwood Village, CO, July 21-25, pp. 109-121.

Hjørland, B. (2017), "Domain analysis”, Knowledge Organization, Vol. 44 No. 6, pp. 436-464.

Hjørland, B. (2018a), "Epistemology of classification with emphasis on Emile Durkheim and Marcel Mauss", in El Hadi, W.M. (Ed.), Fondements épistémologiques et théoriques de la science de l'information-documentation: hommage aux pionniers francophones, Actes du 11e colloque ISKO France 2017, 11-12 Juillet, UNESCO Paris, ISTE Editions, London, pp. 2-9.

Hjørland, B. (2018b), "Indexing: concepts and theory", in Hjørland, B. (Ed.), ISKO Encyclopedia of Knowledge Organization, ISKO, Rome, available at: www.isko.org/cyclo/indexing

Hjørland, B. (2018c), "Library and Information Science (LIS). Part 1", Knowledge Organization, Vol. 45 No. 3, Also (with part 2) in ISKO Encyclopedia of Knowledge Organization, pp. 232-254, available at: www.isko.org/cyclo/lis

Hjørland, B. and Albrechtsen, H. (1995), "Toward a new horizon in information science: domain analysis", Journal of the American Society for Information Science, Vol. 46 No. 6, pp. 400-425. 
Kleineberg, M. (2017), "Integrative levels”, in Hjørland, B. (Ed.), Knowledge Organization, Vol. 44 No. 5, also ISKO Encyclopedia of Knowledge Organization, pp. 349-379, available at: www.isko.org/ cyclo/integrative_levels (accessed June 23, 2018).

Kuhn, T.S. (1962), The Structure of Scientific Revolutions, University of Chicago Press, Chicago, IL.

Leontyev, A.N. (1981), Problems in the Development of the Mind, Progress, Moscow.

Lund, N.W. (2009), "Document theory", Annual Review of Information Science and Technology, Vol. 43 No. 1, pp. 399-432.

Mai, J.E. (2011), “The modernity of classification”, Journal of Documentation, Vol. 67 No. 4, pp. 710-730.

Mai, J.-E. (2013), "Ethics, values, and morality in contemporary library classifications", Knowledge Organization, Vol. 40 No. 3, pp. 242-253.

Ørom, A. (2007), "The concept of information versus the concept of document", in Skare, R., Windfeld Lund, N. and Vårheim, A. (Eds), Document (re)turn. Contributions from A Research field in Transition, Peter Lang, Frankfurt am Main, pp. 53-72.

Poli, R. (2001), "The basic problem of the theory of levels of reality", Axiomathes, Vol. 12 Nos 3-4, pp. 261-283.

Poli, R. (2016), "Nicolai Hartmann", in Zalta, E.N. (Ed.), Stanford Encyclopedia of Philosophy, Metaphysics Research Lab, Stanford University, Stanford, CA, available at: https://plato. stanford.edu/archives/win2017/entries/nicolai-hartmann/ (accessed September 26, 2018).

Popper, K.R. (1972), Objective Knowledge: An Evolutionary Approach, Clarendon Press, Oxford.

Popper, K.R. (1978), "Three worlds: the tanner lecture on human values", delivered at the University of Michigan, April 7, available at: https:/tannerlectures.utah.edu/_documents/a-to-z/p/popper80. pdf (accessed March 29, 2018).

Popper, K.R. (1992), Unended Quest: An Intellectual Autobiography, rev. ed., Routledge, London.

Popper, K.R. and Eccles, J.C. (1977), The Self and its Brain: An Argument for Interactionism, Springer, Berlin.

Robinson, H. (2017), "Dualism", in Zalta, E.N. (Ed.), The Stanford Encyclopedia of Philosophy, Metaphysics Research Lab, Stanford University, Stanford, CA, available at: https:/plato. stanford.edu/archives/fall2017/entries/dualism/

Smiraglia, R.P. (2001), The Nature of "A Work": Implications for the Organization of Knowledge, Scarecrow Press, Lanham, MD.

Smiraglia, R.P. (2002), Works as Entities for Information Retrieval, Haworth Press, New York, NY.

Žumer, M. (2018), "IFLA Library Reference Model (LRM): harmonisation of the FRBR family", Knowledge Organization, Vol. 45 No. 4, pp. 310-318, also available in Hjørland, B. (Ed.), ISKO Encyclopedia of Knowledge Organization, ISKO, Rome, available at: www.isko.org/cyclo/lrm

\section{Corresponding author}

Birger Hjørland can be contacted at: birger.hjorland@hum.ku.dk

For instructions on how to order reprints of this article, please visit our website:

www.emeraldgrouppublishing.com/licensing/reprints.htm

Or contact us for further details: permissions@emeraldinsight.com 